\title{
A COMPARISON OF CHROMOSOME NUMBER AND KARYOTYPE IN SOMATIC CHROMOSOMES OF STANGERIACEAE (CYCADALES)
}

\author{
G. Konubugata*, K. D. Hill $\uparrow$, G. W. Wilsont, K. Kondoß \& \\ L. M. RANDALL
}

Somatic chromosomes at mitotic metaphase of two species and two undescribed populations of Bowenia, and Stangeria eriopus, which were classified in Stangeriaceae, Cycadales, were compared using the standard aceto-orcein staining method. All Bowenia taxa showed a chromosome number of $2 \mathrm{n}=18$, while S. eriopus showed a chromosome number of $2 n=16$. The chromosome number of $2 n=18$ in $B$. 'Kuranda' is reported for the first time. The present karyotype analysis indicates that $B$. 'Kuranda' and another undescribed taxon, $B$. 'Tinaroo', are cytotaxonomically closer to $B$. spectabilis than $B$. serrulata, and that the karyotype of Stangeria is unlikely to have been derived from that of Bowenia by a simple chromosomal change such as centromeric fission and deletion.

Keywords. Chromosome, Cycadales, cytotaxonomy, Stangeriaceae.

\section{INTRODUCTION}

The family Stangeriaceae (Cycadales; Stevenson, 1992) consists of two genera: Bowenia Hook. ex J.D. Hook. and Stangeria (Kunze) Baillon. The genus Bowenia is endemic to Queensland, Australia, and includes two species: B. serrulata (W. Bull) Chamberlain and B. spectabilis Hook. ex J.D. Hook. The two species are distinguished by their leaflet margin and rootstock morphology (Jones, 1993). Bowenia 'Kuranda' and B. 'Tinaroo' are two other entities in this genus that have not yet been formally named and described (Wilson, unpublished). Bowenia 'Kuranda' and B. 'Tinaroo' are morphologically intermediate between B. serrulata and B. spectabilis (Jones, 1993; Wilson, unpublished), but are unlikely to be simple hybrids because the nearest populations of B. serrulata are over $700 \mathrm{~km}$ away. The genus Stangeria is endemic to the east coast of South Africa and consists of only one species: Stangeria eriopus (Kunze) Baillon.

Although some cytotaxonomical studies of the family have been reported previously (Sax \& Beal, 1934; Marchant, 1968; Moretti, 1990; Kokubugata et al., 2000),

* Tsukuba Botanical Garden, National Science Museum, Tokyo, Amakubo, Tsukuba, Ibaraki 305-0005, Japan.

$\dagger$ National Herbarium of New South Wales, Royal Botanic Gardens, Sydney, Mrs Macquaries Road, Sydney, NSW 2000, Australia.

\$ Department of Tropical Plant Science, James Cook University, Cairns 4870, Australia.

$\S$ Laboratory of Plant Chromosome and Gene Stock, Faculty of Science, Hiroshima University, HigashiHiroshima, Hiroshima 739-8526, Japan.

If 54 Cockatoo Court, Caboolture, QLD 4510, Australia. 
differences in karyotypes seemed to vary with different cytotaxonomists, and there have been no cytotaxonomical investigations of $B$. 'Kuranda'. The present study thus aims to investigate their chromosome numbers and karyotypes using the acetoorcein squash method, and to compare the karyotypes of all members of the family Stangeriaceae.

\section{Materials and Methods}

The taxonomic treatment follows Stevenson (1992). Plants of Bowenia investigated in the present study were collected in Queensland, Australia, and cultivated in the greenhouse of the Tsukuba Botanical Garden, National Science Museum, Tokyo (Table 1). A plant of Stangeria eriopus cultivated at the Royal Botanic Gardens, Sydney, was used for the present study. Voucher specimens were deposited in the National Herbarium of New South Wales, Royal Botanic Gardens, Sydney (NSW) and the National Science Museum, Tokyo (TNS).

Pretreatment, fixation, and storage of materials followed Kokubugata \& Kondo (1998). Young leaflets were harvested and pretreated in 4mM 8-hydroxyquinoline at $4{ }^{\circ} \mathrm{C}$ for $8 \mathrm{~h}$, then fixed in acetic ethanol $(1: 3)$ at $4^{\circ} \mathrm{C}$ for $24 \mathrm{~h}$, and transferred to and stored in $70 \%$ ethanol at $-20^{\circ} \mathrm{C}$. The stored leaflets were macerated in $45 \%$ acetic acid at $60^{\circ} \mathrm{C}$ for $3 \mathrm{~min}$ before staining in $2 \%$ aceto-orcein at room temperature for $4 \mathrm{~h}$. They were then squashed in $45 \%$ acetic acid. Orcein-stained chromosomes were classified according to the position of centromeres defined by arm ratio (long arm length/short arm length; Levan et al., 1964). Three mitotic metaphase plates per taxon were measured to obtain mean chromosome length and arm ratio. Chromosomes were then aligned with reference to the arm ratio in each complement for calculating mean chromosome length and arm ratio, and finally, aligned with reference to the chromosome length from the longest to the shortest for the idiogram presented here.

TABLE 1. Stangeriaceae species used in this study

\begin{tabular}{llc}
\hline \hline Species & Origin & Accession no. \\
\hline Bowenia serrulata & Queensland, Australia: Byfield & TBG122889 \\
B. spectabilis & Queensland, Australia: Bellenden Kerr & TBG122893 \\
B. 'Kuranda' & Queensland, Australia: Kuranda & TBG122898 \\
B. 'Tinaroo' & Queensland, Australia: Black Mountain, Timber & TBG122895 \\
& $\quad$ Reserve & RBGS903031 \\
\hline \hline
\end{tabular}

TBG, Tsukuba Botanical Garden, National Science Museum, Tokyo; RBGS, Royal Botanic Gardens, Sydney. 


\section{Results AND Discussion}

All Bowenia species investigated had a chromosome number of $2 \mathrm{n}=18$ (Fig. 1A-D), this being consistent with previous reports (Sax \& Beal, 1934; Marchant, 1968; Moretti, 1990; Kokubugata et al., 2000). On the other hand, Stangeria eriopus had a chromosome number of $2 \mathrm{n}=16$ (Fig. 1E), this also being consistent with previous reports (Sax \& Beal, 1934; Marchant, 1968; Moretti, 1990).

Previous studies of Cycadales cytotaxonomy have been performed by Sax \& Beal (1934), Marchant (1968), and Moretti (1990); unfortunately, however, they did not describe the chromosomal classification used in their studies. In the present study, we assume that 'chromosome with median centromere (m)' and 'chromosome with terminal centromere (t)' defined by Levan et al. (1964) correspond with 'median fiber' and 'terminal fiber' in Sax \& Beal (1934), 'median' and 'terminal' in Marchant (1968), and ' $\mathrm{M}$ ' and ' $\mathrm{T}$ ' in Moretti (1990). We also assume that 'chromosome with submedian centromere (sm)' and 'chromosome with subterminal centromere (st)'

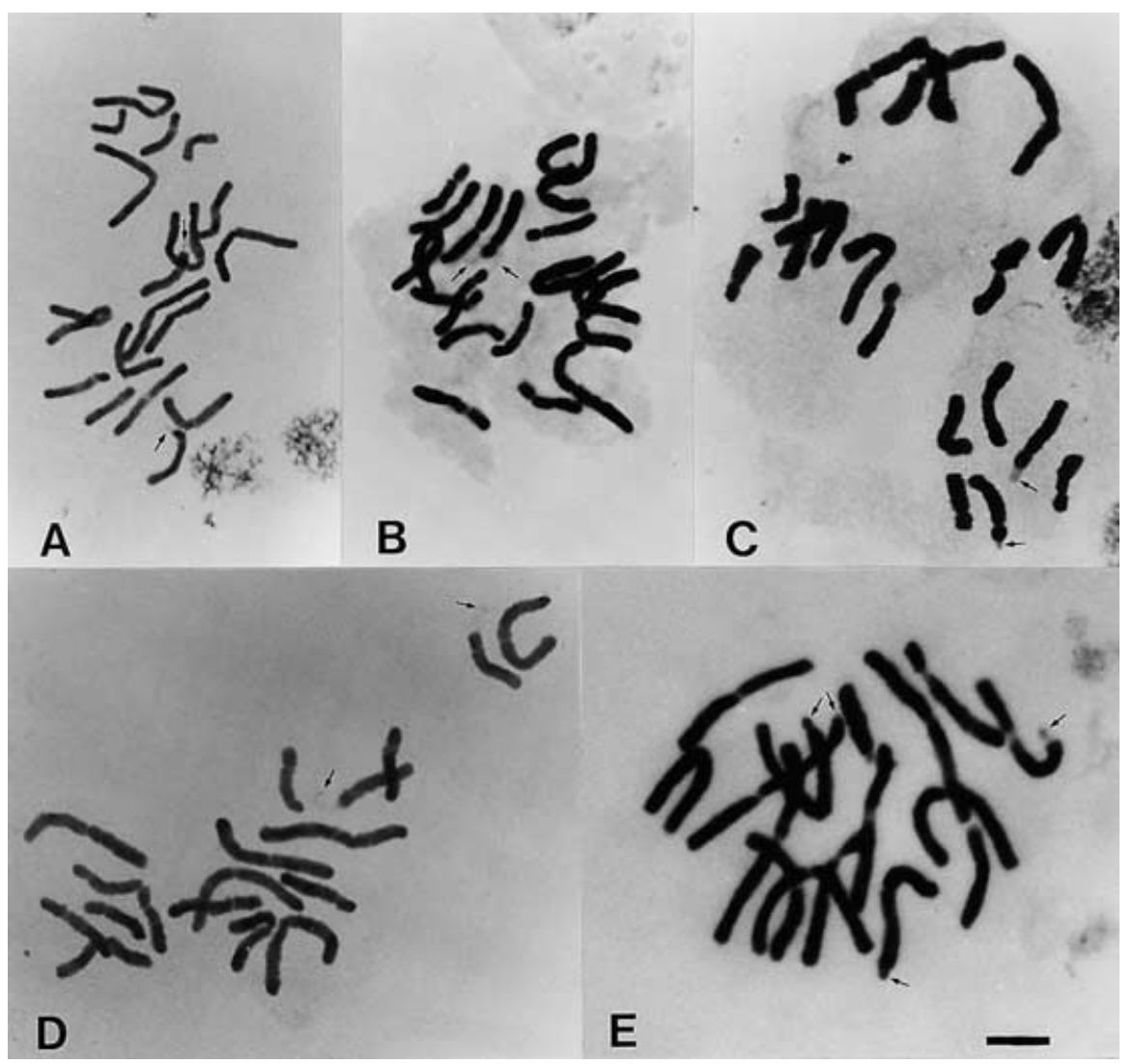

FIG. 1. Chromosomes of Stangeriaceae at mitotic metaphase stained with aceto-orcein: A, Bowenia serrulata; B, B. spectabilis; C, B. 'Kuranda'; D, B. 'Tinaroo'; E, Stangeria eriopus. Arrows indicate satellites. Scale bar $=10 \mu \mathrm{m}$. 
defined by Levan et al. (1964) correspond with 'sub-term. fiber' in Sax \& Beal (1934), 'subterminal' in Marchant (1968), and 'S' or 'A' in Moretti (1990).

The karyotype of B. serrulata consists of $10 \mathrm{~m}+3 \mathrm{sm}+5 \mathrm{st}$ (Fig. 2A, Table 2). This is very close to the karyotype reported by Kokubugata et al. (2000), but differs from that observed in the same species by Sax \& Beal (1934), who reported $12 \mathrm{~m}+6$ st (or $\mathrm{sm}$ ). The tenth chromosome was significantly shorter than the ninth one (Fig. 2A). There is a small possibility that the quantitative difference in chromosome length might be heteromorphic, and might correlate with the sex determination function of the chromosome. Unfortunately, the sex of the $B$. serrulata plant investigated could not be determined as it was a seedling. The karyotype of B. spectabilis consists of $8 \mathrm{~m}+6 \mathrm{sm}+4 \mathrm{st}$ (Fig. 2B, Table 2). This is very close to the karyotype reported by Kokubugata et al. (2000), but differs from Moretti's (1990) report of $12 \mathrm{~m}+6$ st (or sm). The karyotype of $B$. 'Kuranda' consists of $8 \mathrm{~m}+6 \mathrm{sm}+4 \mathrm{st}$ (Fig. 2C, Table 2).

A

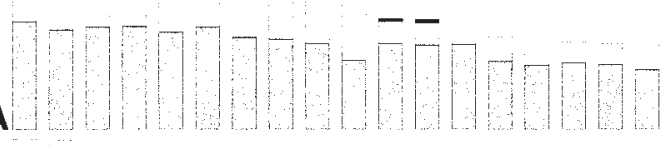

B
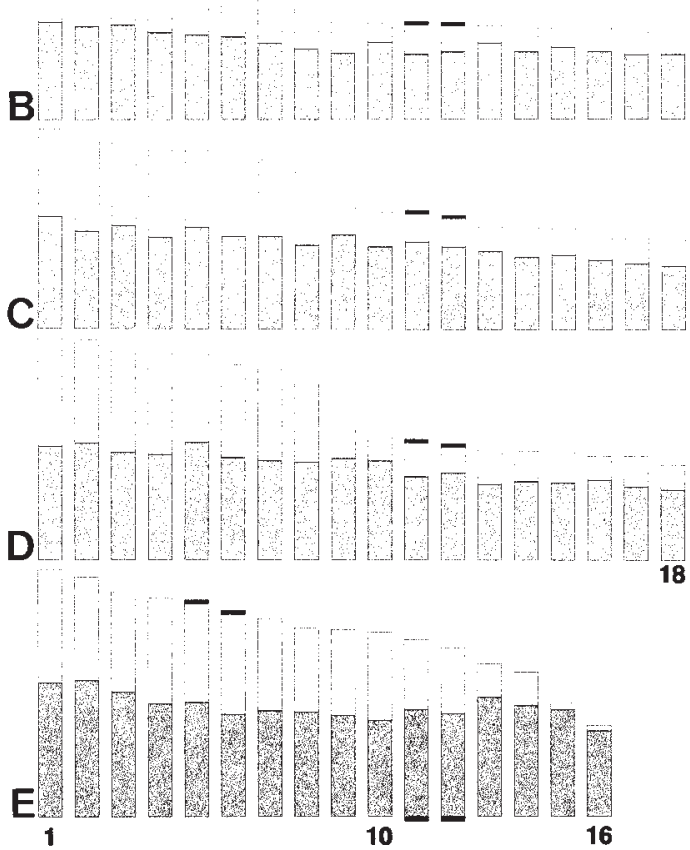

FIG. 2. Idiograms of Stangeriaceae based on means of three chromosome complements at mitotic metaphase: A, Bowenia serrulata; B, B. spectabilis; C, B. 'Kuranda'; D, B. 'Tinaroo'; E, Stangeria eriopus. Shaded areas: long arm; open areas: short arm; solid areas: satellites. 
TABLE 2. Mean length and arm ratio of three chromosomes of five Stangeriaceae taxa

\begin{tabular}{|c|c|c|c|c|c|c|c|c|c|c|}
\hline \multirow{2}{*}{$\begin{array}{l}\text { Chromosome } \\
\text { no. }\end{array}$} & \multicolumn{2}{|c|}{$\begin{array}{l}\text { Bowenia } \\
\text { serrulata }\end{array}$} & \multicolumn{2}{|c|}{ B. spectabilis } & \multicolumn{2}{|c|}{ B. 'Kuranda' } & \multicolumn{2}{|c|}{ B. 'Tinaroo' } & \multicolumn{2}{|c|}{$\begin{array}{l}\text { Stangeria } \\
\text { eriopus }\end{array}$} \\
\hline & $\mathrm{L}$ & $\mathrm{R}(\mathrm{F})$ & $\mathrm{L}$ & $\mathrm{R}(\mathrm{F})$ & $\mathrm{L}$ & $\mathrm{R}(\mathrm{F})$ & $\mathrm{L}$ & $\mathrm{R}(\mathrm{F})$ & $\mathrm{L}$ & $\mathrm{R}(\mathrm{F})$ \\
\hline $1 \mathrm{st}$ & 26.6 & $1.2(\mathrm{~m})$ & 23.7 & $1.2(\mathrm{~m})$ & 27.3 & $1.3(\mathrm{~m})$ & 29.3 & $1.0(\mathrm{~m})$ & 30.3 & $1.2(\mathrm{~m})$ \\
\hline $2 \mathrm{nd}$ & 25.8 & $1.1(\mathrm{~m})$ & 23.6 & $1.1(\mathrm{~m})$ & 25.6 & $1.1(\mathrm{~m})$ & 29.1 & $1.1(\mathrm{~m})$ & 29.4 & $1.3(\mathrm{~m})$ \\
\hline $3 \mathrm{rd}$ & 25.2 & $1.2(\mathrm{~m})$ & 22.4 & $1.3(\mathrm{~m})$ & 25.5 & $1.2(\mathrm{~m})$ & 27.7 & $1.1(\mathrm{~m})$ & 27.6 & $1.2(\mathrm{~m})$ \\
\hline 4 th & 25.0 & $1.2(\mathrm{~m})$ & 22.2 & $1.1(\mathrm{~m})$ & 24.5 & $1.0(\mathrm{~m})$ & 27.3 & $1.0(\mathrm{~m})$ & 26.8 & $1.1(\mathrm{~m})$ \\
\hline 5 th & 24.6 & $1.1(\mathrm{~m})$ & 20.9 & $1.2(\mathrm{~m})$ & 24.5 & $1.3(\mathrm{~m})$ & 27.2 & $1.3(\mathrm{~m})$ & 26.1 & $1.2(\mathrm{~m})$ \\
\hline 6th & 24.3 & $1.3(\mathrm{~m})$ & 20.8 & $1.1(\mathrm{~m})$ & 24.1 & $1.1(\mathrm{~m})$ & 25.8 & $1.1(\mathrm{~m})$ & 24.8 & $1.0(\mathrm{~m})$ \\
\hline 7 th & 24.2 & $1.0(\mathrm{~m})$ & 20.3 & $1.0(\mathrm{~m})$ & 23.2 & $1.2(\mathrm{~m})$ & 25.2 & $1.1(\mathrm{~m})$ & 24.3 & $1.2(\mathrm{~m})$ \\
\hline 8 th & 23.2 & $1.1(\mathrm{~m})$ & 18.2 & 1.1 (m) & 21.6 & 1.1 (m) & 23.2 & $1.3(\mathrm{~m})$ & 23.1 & $1.2(\mathrm{~m})$ \\
\hline 9th & 22.4 & $1.1(\mathrm{~m})$ & 13.0 & $2.1(\mathrm{sm})$ & 16.7 & $3.4(\mathrm{st})$ & 17.2 & $3.5(\mathrm{st})$ & 22.9 & $1.2(\mathrm{~m})$ \\
\hline 10th & 18.5 & $1.0(\mathrm{~m})$ & 12.9 & $4.0(\mathrm{st})$ & 16.1 & $2.4(\mathrm{sm})$ & 16.2 & $4.2(\mathrm{st})$ & 22.6 & $1.1(\mathrm{~m})$ \\
\hline 11 th & 14.4 & 4.0 (st) & 12.6 & $2.2(\mathrm{sm})$ & 15.9 & $3.1(\mathrm{st})$ & 15.5 & $2.4(\mathrm{~m})$ & 21.7 & $1.5(\mathrm{~m})$ \\
\hline 12th & 14.3 & $3.8(\mathrm{st})$ & 12.5 & $2.6(\mathrm{sm})$ & 15.2 & $2.9(\mathrm{sm})$ & 14.9 & 3.4 (st) & 20.7 & $1.6(\mathrm{~m})$ \\
\hline 13th & 13.9 & 4.6 (st) & 12.5 & $4.4(\mathrm{st})$ & 14.1 & 3.1 (st) & 14.6 & $2.2(\mathrm{sm})$ & 18.7 & $3.6(\mathrm{st})$ \\
\hline 14th & 12.4 & $2.8(\mathrm{sm})$ & 12.2 & $2.8(\mathrm{sm})$ & 14.0 & $2.4(\mathrm{sm})$ & 14.4 & $2.6(\mathrm{sm})$ & 17.7 & $3.3(\mathrm{st})$ \\
\hline 15 th & 11.8 & $2.7(\mathrm{sm})$ & 12.2 & 3.7 (st) & 13.8 & $2.8(\mathrm{sm})$ & 14.3 & $2.5(\mathrm{sm})$ & 13.9 & $16.4(t)$ \\
\hline 16th & 11.7 & $3.2(\mathrm{st})$ & 12.1 & $2.9(\mathrm{sm})$ & 12.5 & $3.2(\mathrm{st})$ & 13.8 & 3.3 (st) & 11.2 & $15.0(\mathrm{t})$ \\
\hline 17 th & 11.5 & 3.1 (st) & 11.6 & $2.9(\mathrm{sm})$ & 12.5 & $2.6(\mathrm{sm})$ & 13.8 & $2.4(\mathrm{sm})$ & - & - \\
\hline 18th & 11.3 & $2.4(\mathrm{sm})$ & 11.2 & $3.3(\mathrm{st})$ & 12.3 & $2.4(\mathrm{sm})$ & 12.6 & $2.8(\mathrm{sm})$ & - & - \\
\hline
\end{tabular}

L, chromosome length $(\mu \mathrm{m}) ; \mathrm{R}$, arm ratio; $\mathrm{F}$, chromosome form according to the position of centromeres defined by arm ratio of long arm length/short arm length (Levan et al., 1964); m, chromosome with median centromere (1.0-1.7); sm, chromosome with submedian centromere (1.8-3.0); st, chromosome with subterminal centromere (3.1-7.0); t, chromosome with terminal centromere $(7.1-\infty)$.

The karyotype of $B$. 'Kuranda' is reported here for the first time. The karyotype of B. 'Tinaroo' consists of $8 \mathrm{~m}+6 \mathrm{sm}+4 \mathrm{st}$ (Fig. 2D, Table 2). This is very close to the karyotype reported by Kokubugata et al. (2000).

Morphologically, B. serrulata has leaflets with toothed margins and a muchbranched rootstock, while $B$. spectabilis has leaflets with entire margins and a sparingly branched rootstock (Jones, 1993). On the other hand, $B$. 'Kuranda' and $B$. 'Tinaroo' are morphologically intermediate in some respects between $B$. serrulata and $B$. spectabilis, i.e. they have toothed leaflets similar to those of $B$. serrulata, and sparingly branched rootstocks similar to those of B. spectabilis (Jones, 1993; Wilson, unpublished). A morphological difference between $B$. 'Kuranda' and B. 'Tinaroo' is that the leaflets of the former are larger and thinner than those of the latter (Wilson, unpublished). In the present investigation, although the chromosome number of all Bowenia material was found to be $2 \mathrm{n}=18$, the karyotype of $B$. 'Kuranda' and $B$. 'Tinaroo' was cytotaxonomically more similar to that of B. spectabilis (with eight chromosomes with median centromeres) than to that of $B$. serrulata (with ten chromosomes with median centromeres) (Fig. 2, Table 2). Bowenia 
serrulata and $B$. spectabilis are too widely distributed for them to hybridize, and thus, according to Jones (1993), B. 'Tinaroo' is not a hybrid of the two Bowenia species. Norstog \& Nicholls (1997) indicated that $B$. 'Tinaroo' is a variety of $B$. spectabilis, and the present results support the hypotheses of both Jones (1993) and Norstog \& Nicholls (1997).

The karyotype of S. eriopus consists of $12 \mathrm{~m}+2 \mathrm{st}+2 \mathrm{t}$ (Fig. 2E, Table 2). Two of twelve chromosomes with median centromeres showed an arm ratio very close to $1.8: 1$, the lowest extreme of the arm ratio range of submedian centromeres according to Levan et al. (1964), and they were aligned in the eleventh and twelfth positions with reference to mean chromosome length (Fig. 2E, Table 2). Sax \& Beal (1934) reported the karyotype of $S$. eriopus to consist of $12 \mathrm{~m}+2 \mathrm{st}$ (or $\mathrm{sm})+2 \mathrm{t}$, whereas Marchant (1968) and Moretti (1990) reported it to consist of $10 \mathrm{~m}+4 \mathrm{st}$ (or sm) $+2 \mathrm{t}$. Although in the strict sense the karyotype of $S$. eriopus in the present study was closer to that reported by Sax \& Beal (1968) than that reported by Marchant (1968) and Moretti (1990), it is likely that the eleventh and twelfth chromosomes of $S$. eriopus in the present observation correspond with two of four chromosomes with submedian (or subterminal) centromeres indicated by Marchant (1968) and Moretti (1990). Among Cycadales, the karyotype of S. eriopus was most similar to that of Ceratozamia mexicana Brong., which had a chromosome number of $2 \mathrm{n}=16$ and karyotype of $12 \mathrm{~m}+2 \mathrm{st}$ (or sm) $+2 \mathrm{t}$ (Sax \& Beal, 1934; Marchant, 1968; Moretti, 1990; Kokubugata \& Kondo, 1998).

A terminal satellite was located on the short arm of two chromosomes with subterminal centromeres (the eleventh and the twelfth) in all Bowenia (Fig. 1A-D, arrows), this verifying the previous report by Kokubugata et al. (2000). On the other hand, a satellite was located on the terminal region of the short arm of two chromosomes with median centromeres (the fifth and sixth) and on the terminal region of the long arm of two chromosomes with median centromeres (the eleventh and twelfth) in S. eriopus (Fig. 1E, arrows), this being very close to the observation reported by Marchant (1968).

In the karyotype evolution of Cycadales, Moretti (1990) hypothesized that Stangeria might have been derived from Bowenia by centromeric fission of two chromosomes with median centromeres, and loss of two chromosomes with submedian centromeres and two chromosomes with terminal centromeres; or by centromeric fission of two chromosomes with submedian centromeres, and loss of two chromosomes with median centromeres and the short arm of two chromosomes with submedian centromeres. If the chromosomal change hypothesized by Moretti (1990) had occurred in the evolution from Bowenia to Stangeria, two satellite chromosomes with submedian centromeres should appear in the chromosome complement of Stangeria. This is because the satellites on the two chromosomes of Bowenia are ribosomal DNA regions (Kokubugata et al., 2000) and essential sites for the genome. Consequently it is expected that these two satellite chromosomes would not be deleted in the evolution from Bowenia to Stangeria. However, the present study shows satellites located on four chromosomes with median centromeres of Stangeria. Thus, 
these results suggest that the progress of chromosomal evolution from Bowenia to Stangeria could not have occurred by simple centromeric fission and loss. Moretti (1990) commented that his scheme was just a 'working hypothesis', and that further investigation was necessary to analyse karyotype evolution in Cycadales. The present investigation showed some different karyotypes from previous reports (Sax \& Beal, 1934; Marchant, 1968; Moretti, 1990), and there is a slight possibility that the differences might occur between different accessions of the same species. Fortunately, Marchant (1968) and Moretti (1990) described the sources of accessions examined and it might be necessary to investigate their morphological characters. Recently, chromosome banding techniques have been applied to somatic chromosomes in Cycadales, for example, using fluorescent in situ hybridization of ribosomal DNA probes (Kokubugata \& Kondo, 1998; Kokubugata et al., 2000). The application of this technique to the observation of chromosomes in Stangeria is essential for analyses of the chromosomal relationships within the family Stangeriaceae and to the other cycads.

\section{ACKNOWLEDGEMENTS}

We are grateful to the Senior Editor and the referees for their helpful suggestions. This research was partly supported by the Sasakawa Scientific Research Grant from the Japan Science Society.

\section{REFERENCES}

Jones, D. L. (1993). Cycads of the World. Washington, DC: Smithsonian Institution Press. Kokubugata, G. \& Kondo, K. (1998). Comparative karyotype analysis of Ceratozamia mexicana and Microcycas calocoma (Zamiaceae) using fluorochrome banding (CMA/DAPI) and fluorescence in situ hybridization of ribosomal DNA. Plant Syst. Evol. 210: 41-50.

Kokubugata, G., Kondo, K., Wilson, G. W., Randall, L. M., Schnas, A. \& Morris, D. K. (2000). Comparison of karyotype and rDNA distribution in somatic chromosomes of Bowenia species (Stangeriaceae, Cycadales). Aust. Syst. Bot. 13: 15-20.

Levan, A., Fredga, K. \& Sandberg, A. A. (1964). Nomenclature for centromeric position on chromosomes. Hereditas 52: 201-220.

MaRChANT, C. J. (1968). Chromosome patterns and nuclear phenomena in the cycad families Stangeriaceae and Zamiaceae. Chromosoma (Berl.) 24: 100-134.

Moretti, A. (1990). Cytotaxonomy of cycads. Mem. New York Bot. Gard. 57: 114-122.

Norstog, K. \& Nicholls, T. J. (1997). The Biology of the Cycads. Ithaca, NY: Cornell University Press.

Sax, K. \& Beal, J. M. (1934). Chromosomes of the Cycadales. J. Arnold Arbor. 15: $255-258$.

Stevenson, D. W. (1992). A formal classification of the extant cycads. Brittonia 44: $220-223$. 